\title{
Bioequivalence study of two formulations containing isotretinoin in fed condition in Colombian healthy volunteers
}

\begin{abstract}
This is a pharmacokinetic trial that evaluates under fed conditions two formulations containing $20 \mathrm{mg}$ of Isotretinoin, with the aim to compare the Bioavailability, between the Test Product (Isoface ${ }^{\circledR}$ Isotretinoin from Procaps S.A. Laboratory, Colombia) and the Reference Product (Roaccutane ${ }^{\circledR}$ Isotretinoin from Catalent Germany Laboratory, Eberbach GMBH, Germany.), to be able to declare Bioequivalence between both formulations. The same formulations were previously studied by these authors under fasting conditions. For this trial, an open, cross-over, randomized study of two periods and two sequences was carried out, with a single dose of $40 \mathrm{mg}$ of Isotretinoin in fed conditions, in 28 healthy male volunteers; washing period was 14 days between each period. For results presentation, Plasma concentration ratio Vs Time curves were runned until hour 72. In order to identify the concentration provided by the studied formulation, the baseline status of each volunteer which was constructed with 3 concentrations prior to the administration of the study drug was eliminated from the analysis. The analytical method employed was high performance liquid chromatography with tandem mass spectrometry detector, HPLC MS/MS, for identification and quantification of Isotretinoin in plasma. The main pharmacokinetic parameters for the Reference Product Vs the Test Product were: $\mathrm{T}_{\max } 5.3$ Vs 5.6hours, $\mathrm{C}_{\max } 374.6$ Vs $385.1 \mathrm{ng} /$ $\mathrm{mL}, \mathrm{AUC}_{0-\mathrm{t}} 6421.3 \mathrm{Vs} 6590.0 \mathrm{hr} * \mathrm{ng} / \mathrm{mL}$ and $\mathrm{AUC}_{0 \text {-inf }} 7484.9 \mathrm{Vs} 7233.2 \mathrm{hr} * \mathrm{ng} / \mathrm{mL}$.

Confidence interval calculation of data with logarithmic transformation showed confidence intervals for the variables $\mathrm{C}_{\text {max }}, \mathrm{AUC}_{\text {o-t }}$, and $\mathrm{AUC}_{0 \text {-Inf }}$ within the values $80-125 \%$, accepted by the F.D.A. and by the European Medicines Agency EMA in their bioavailability and bioequivalence guidelines to accept the Bioequivalence hypothesis between the two formulations under study, and thus, declare Bioequivalence and interchangeability of the Procaps S.A. Laboratory product (Test Product), with the Catalent Germany Laboratory, Eberbach GMBH product (Reference Product).
\end{abstract}

Keywords: bioequivalence, isotretinoin, acne, bioavailability, pharmacokinetics, health
Volume 5 Issue 6 - 2018

\author{
Mauricio Vargas Malagon, ' Villarraga, ${ }^{2}$ Mantilla \\ $\mathrm{P}^{3}$ Montenegro L, ${ }^{4}$ Ortega $\mathrm{O}^{5}$ \\ 'Pharmacologist, Scientific Director Pharmacology Unit \\ Universidad de La Sabana, Colombia \\ ${ }^{2}$ Pharmacologist, Study's Medical Coordinator, Colombia \\ ${ }^{3}$ Corporate Medical Director Procaps S.A, Colombia \\ ${ }^{4}$ Chief Medical Support Procaps S. A, Colombia \\ ${ }^{5}$ Chief Medical Support Procaps S.A, Colombia
}

Correspondence: Mauricio Vargas Malagon, Pharmacologist, Scientific Director Pharmacology Unit Universidad de La Sabana, Bogotá-Colombia, Email mavricio.vargas@unisabana.edu.co

Received: October 10,2018 | Published: November 06, 2018

\section{Introduction}

Retinoids are intracrine and paracrine mediators that intervene in apoptosis, proliferation and reproduction of cell differentiation, by binding to nuclear retinoic receptors. Isotretinoin in oral presentation has as its main effect sebaceous secretion reduction, which is reached in $80 \%$ by the fourth week of treatment. ${ }^{1}$ Isotretinoin's gastrointestinal absorption exhibits a high variability, which is greatly influenced by the presence or absence of food. ${ }^{2}$

Pharmacokinetic studies of $40 \mathrm{mg}$ of Isotretinoin in healthy volunteers who were given the medication in fasting conditions, reported concentrations of 167 to $459 \mathrm{ng} / \mathrm{mL}$ at 3.2 hours. $^{3}$ But recommendation for Isotretinoin's use is to be administered after eating food, as its bioavailability increases between $1 \frac{1}{2}$ to 2 times, even though elimination half-life after a dose of $40 \mathrm{mg}$ is 10 to 20 hours in volunteers, being up to 90 hours in patients ${ }^{2,3}$

The results obtained in our first study carried out in Colombian population under fasting conditions with these same formulations, ${ }^{4}$ evidenced for Isoface ${ }^{\circledR}$ from Procaps Product the following values: Tmax 2.6 hours, Cmax 190.5ng/mL, AUC $_{0-\mathrm{t}} 3003.8 \mathrm{hr} * \mathrm{ng} / \mathrm{mL}$ and $\mathrm{AUC}_{0 \text {-inf }} 3726.3 \mathrm{hr} * \mathrm{ng} / \mathrm{mL}$.
According to the FDA and EMA, two products are bioequivalent if they contain the same active ingredient and if the kinetic studies do not show significant differences in the AUC and Cmax parameters, showing confidence interval in the range of 0.80 to $1.25{ }^{5,6}$ Here are the results of a single dose study of $40 \mathrm{mg}$ of strength, comparing the bioavailability of two formulations of Isotretinoin, one from Procaps S.A. Colombia named Isoface ${ }^{\circledR}$ against the formulation of the Catalent Germany laboratory named Roaccutane ${ }^{\circledR}$

\section{Study design}

An open, crossed, with a single dose regimen of $40 \mathrm{mg}$ and randomized design was established, with two periods, two sequences, in fed condition, and a washout of 14 days between each period. A total of 28 healthy volunteers participated in the present Bioequivalence study. To calculate the number of volunteers for this Bioequivalence trial, the formula proposed by Marzo and Balant (1995) ${ }^{7}$ was used $\mathrm{n} \geq\left(15,68 \mathrm{xCV}^{2}\right) / \Delta$. Where intraindividual variation coefficient reported by the technical datasheet of the reference product is: $25 \%{ }^{8}$ Therefore: $\mathrm{n} \geq\left(15.68 \times 25^{2}\right) / 20^{2}=24.5$. It was defined to conduct the study with 28 volunteers based on the high power and significance level that the formula gives, and 4 additional volunteers in order to prevent volunteer's dropouts or withdrawal. 


\section{Materials and methods}

\section{Study formulations}

\section{Test drug}

Isoface ${ }^{\circledR} 20 \mathrm{mg}$ Isotretinoin, for oral administration, manufactured and distributed by Procaps Laboratories S.A., Colombia, Lot 1104962

\section{Reference drug}

Roaccutane ${ }^{\circledR} \quad 20 \mathrm{mg}$ Isotretinoin, for oral administration, manufactured and distributed by Catalent Germany, Germany. Lot B2025B01

\section{Subjects}

Healthy volunteers diagnosed by physical examination and laboratory tests to determine their correct hepatic, cardiac, renal function, etc. and that they met the inclusion criteria reflected in the study's protocol.

\section{Obtaining informed consent}

Volunteers signed the informed consent form authorized by the Ethics Committee of Universidad de La Sabana, which complies with the national regulations of Resolutions 008430 of 1993 and 002378 of 2008 of the Ministry of Social Protection (Colombia), ${ }^{9}$ and the Helsinki Declaration. ${ }^{10}$

\section{All volunteers signed informed consent}

The 28 selected healthy volunteers met the inclusion criteria of the study: male volunteers, average age 29.7 years, average weight of $69.3 \mathrm{~kg}$, average height of $171.5 \mathrm{~cm}$ and average BMI of $23.6 \mathrm{~kg} / \mathrm{m}^{2}$.

\section{Drug administration}

For the medicine administration, volunteers received a standardized diet. Breakfast was programmed with high lipids content, approximately 50 percent, and high caloric content, approximately 800 to $1000 \mathrm{kcal} .{ }^{11}$ This meal was administered 30 minutes before the investigational drug was administered, that is 2 capsules of $20 \mathrm{mg}$ each, to each volunteer. The dose was ingested with $200 \mathrm{~mL}$ of water. After this, volunteers remained seated for the next 4hours ${ }^{12}$

During the hospitalization period in the clinic, two meals (breakfast and lunch) and two snacks (one in the morning and one in the afternoon) were provided to the volunteers. ${ }^{13}$

All volunteers received Isoface $\AA$ or Roaccutane $(\AA$ according to randomization. Blood samples were taken in the following times: -10 , -2 and 0 hours before drug administration, and 1, 2, 2.5, 3, 3.5, 4, 6, $12,24,48$ and 72 hours after. Plasma was separated from the samples and stored at -20 Celsius degrees for further analysis. After 7 halflives of the active study medication, that is to say 14 days of washout, the second study period took place. ${ }^{14}$

\section{Validation of the analytical method}

The validation procedure of bioanalytical methodology established by QUASFARM\&F S.A. was performed. In order to quantify the active metabolite Isotretinoin, the metabolites product of the elimination do not have important active behaviors, reason why those metabolites were not quantified..$^{15}$ Conditions were the same as the ones in the previous study published by us. ${ }^{4}$

\section{Pharmacokinetic analysis}

The WinNonlin 5.3 program (Pharsight Corporation, Cary USA) through a non-compartmental analysis was used. The pharmacokinetic parameters evaluated were Maximum concentration $\left(\mathrm{C}_{\max }\right)$ and the time to reach it $\left(\mathrm{t}_{\max }\right)$, as currently recommended by the $\mathrm{FDA}^{5}$ and the European Agency for evaluation of medicines (EMA), ${ }^{6} \mathrm{AUC}_{\text {total }}$ and $\mathrm{AUC}_{0-\mathrm{t}}$, between time zero and the last time with detectable concentrations. ${ }^{16}$

\section{Statistic analysis}

Possible effects for the variables sequence, period, volunteer or treatment, were evaluated by variance analysis, applying an F-test with $0.05 \%$ alpha.

Bioequivalence criteria were established with confidence interval of $90 \%$ of the relations of $\mathrm{C}_{\max }$ and $\mathrm{AUC}$ that must be within the range of $80-125 \%$ of acceptability. ${ }^{16,17}$ These analysis were performed using the WinNonlin version 5.3 software.

\section{Results}

28 healthy male volunteers completed the two periods and were included in the pharmacokinetic and statistical analysis.

Graph 1 shows the bioavailability of both Isotretinoin's formulations (Isoface ${ }^{\circledR}$ from Procaps S.A., Colombia) and (Roaccutane ${ }^{\circledR}$ from Catalent Germany) in 28 healthy male volunteers Table 1.

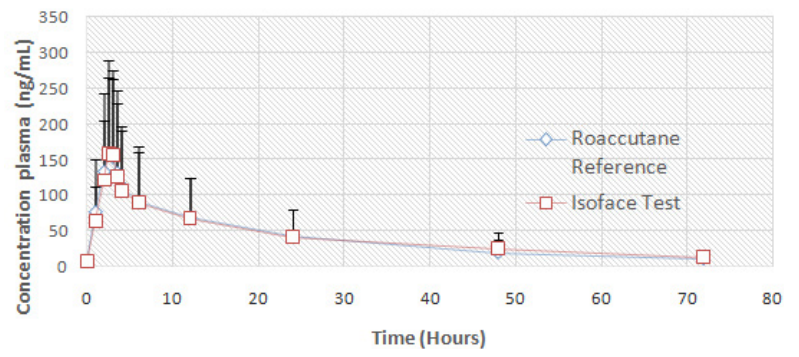

Graph I Bioavailability curve (concentration vs. time) obtained after an Isotretinoin dose in fed condition of the Test product (Isoface $\circledR$ from Procaps S.A., Colombia) and the Reference product (Roaccutane ${ }^{\circledR}$ from Catalent Germany, Eberbach GMBH, Germany).

Table I Analytical conditions

\begin{tabular}{|c|c|}
\hline Column & Fortis $1.7 \mu \mathrm{m} \mathrm{Cl} 850 \times 2.1 \mathrm{~mm}$ \\
\hline Column Code & U-LI-c-I-ex \\
\hline Precolumn & N.A. \\
\hline Column Temperature & $30^{\circ} \mathrm{C}$ \\
\hline Mobile Phase Flow & $0.2 \mathrm{~mL} / \mathrm{min}$ \\
\hline Column Pressure & 80Bar \\
\hline Mobile Phase & Acetonitrile:Water 90:10 \\
\hline Autosampler Temperature & N.A. \\
\hline Injection Volume & $10 \mu \mathrm{m}$ \\
\hline Run Time & 3minutes \\
\hline Holding time & I.I min Acitretine, $1.6 \mathrm{~min}$ Isotretinoine \\
\hline Integration Parameters & Agilent \\
\hline Extraction Type & Liquid-liquid \\
\hline Extraction Agent & Hexane:Isopropanelol 95:5 \\
\hline
\end{tabular}

Quantification limit was Ing/mL. ${ }^{13-15}$ 
In Table 2, the mean values of the pharmacokinetic parameters obtained from all the volunteers (mean $\pm \mathrm{SD})$ with Isoface ${ }^{\circledR}$ from Procaps S.A., Colombia and Roaccutane ${ }^{\circledR}$ from Catalent Germany, can be seen. For the pharmacokinetic analysis a mean value was obtained. Basal points were taken at-10-2 and 0hours. This value was eliminated from the individual values obtained for each volunteer of the plasma concentrations contributed by the studied formulations. The main pharmacokinetic parameters for the Reference Product Vs the Test Product were: $T_{\max } 5.3$ Vs 5.6 hours, $C_{\max } 374.6$ Vs $385.1 \mathrm{ng} /$ $\mathrm{mL}, \mathrm{AUC}_{0-\mathrm{t}} 6421.3 \mathrm{Vs} 6590.0 \mathrm{hr} * \mathrm{ng} / \mathrm{mL}$ and $\mathrm{AUC}{ }_{0 \text {-inf }} 7484.9 \mathrm{Vs}$ 7233.2hr*ng/mL.
Results obtained in the previous study carried out by these same researchers, in Colombian volunteers in fasting conditions, and with the same drugs, showed the following results for the Test Product Vs the Reference Product: $\mathrm{T}_{\max } 2.6$ Vs 2.8 hours, $\mathrm{C}_{\max } 190.5 \mathrm{Vs} 186.5 \mathrm{ng} /$ $\mathrm{mL}, \mathrm{AUC}_{0-\mathrm{t}} 3003.8 \mathrm{Vs} 2933.5 \mathrm{hr} * \mathrm{ng} / \mathrm{mL}$ and $\mathrm{AUC}_{0 \text {-inf }} 3726.3 \mathrm{Vs}$ $3521.2 \mathrm{hr} * \mathrm{ng} / \mathrm{mL}^{4}$

Table 3 shows the confidence intervals for the variables $\mathrm{C}_{\max }$, $\mathrm{AUC}_{\mathrm{o}-\mathrm{t}}$, and $\mathrm{AUC}_{0-\operatorname{Inf}}$ within the values $80-125 \%$

The coefficient of intrasubject variation for each variable obtained in this study was: $\mathrm{C}_{\max } \mathrm{CV} \%$ intrasubject $35.4 \%, \mathrm{AUC}_{0-\mathrm{t}} \mathrm{CV} \%$ intrasubject $25.8 \%$ and $\mathrm{AUC}_{\text {Inf }} \mathrm{CV} \%$ intrasubject $26.3 \%$.

Table 2 Isotretinoin pharmacokinetic parameters of the Test product (Isoface $®$ from Procaps S.A., Colombia) and the Reference Product (Roaccutane $®$ from Catalent Germany, Eberbach GMBH, Germany) followed by a single oral dose in fed condition. Pharmacokinetic parameters summary data adjusted to baseline

\begin{tabular}{|c|c|c|c|c|c|c|}
\hline Treatment & Elimination Speed (I/hr) & Half Life(hr) & $\mathbf{T}_{\max (\mathrm{hr})}$ & $C_{\max }(n g / m L)$ & $\begin{array}{l}\text { AUC }_{0-\mathrm{t}} \\
\text { (hr*ng/mL) }\end{array}$ & $\begin{array}{l}\text { AUC }_{0-\operatorname{lnf}} \\
\text { (hr*ng/mL) }\end{array}$ \\
\hline Reference & 0.041 & 13.1 & 5.3 & 374.6 & 6421.3 & 7484.9 \\
\hline Test & 0.046 & 13.2 & 5.6 & 385.1 & 6590 & 7233.2 \\
\hline
\end{tabular}

Table $390 \%$ confidence intervals for Isotretinoin formulations (Test and Reference products) after their administration to healthy volunteers in fed conditions

\begin{tabular}{|c|c|c|c|}
\hline \multirow[b]{2}{*}{ Parameter } & \multirow[b]{2}{*}{ Units } & \multicolumn{2}{|c|}{ Standard CI 90\% (Test/Reference) } \\
\hline & & Ratio\% & 80125 \\
\hline $\operatorname{Ln}\left(C_{\max }\right)$ & $\mathrm{ng} / \mathrm{mL}$ & 102.62 & $87.72 \mid 20.06$ \\
\hline $\operatorname{Ln}\left(A \cup C_{\text {all }}\right)$ & $\mathrm{hr} * \mathrm{ng} / \mathrm{mL}$ & 95.25 & $84.81 \quad 106.97$ \\
\hline $\operatorname{Ln}\left(A \cup C_{\text {inf-obs }}\right)$ & hr*ng/mL & 92.96 & 82.59104 .63 \\
\hline
\end{tabular}

\section{Discussion}

Bioequivalence studies are the subrogated evidence that generic drugs will have similar efficacy and safety profile. ${ }^{17}$ The use of generic medications favors health resources control.

Performance of the in vitro study allowed us to compare the two formulations studied in order to declare the Pharmaceutical
Equivalence and qualify the quality attributes of the same. But in fact, the in vivo studies are the ones that allow us to declare the interchangeability of the active principles that do not comply with bio-exemption. ${ }^{18}$ With this, we would achieve financial resources control as developed countries do with high regulatory requirements for generic drugs; countries who increase year after year the use of generics which demonstrate bioequivalence.

The study was completed with the 28 volunteers initially included, and the adverse events related in Table 4 ocurred. The washout period was enough and guaranteed the absence of carryover effect. ${ }^{19}$

We can show how food administration before the drug ingestion impacts on a greater quantity of active ingredient available to generate pharmacodynamic effects, when compared to fasted conditions. ${ }^{4}$

In the case of Isotretinoin, the incorporation of a bioequivalent formulation to the pharmacological treatment for nodule-cystic acne or with a severe scar component, contributes to the clinical objective and costs control of this pathology.

Table 4 Distribution of adverse reactions reported by medication and the causal relationship related to each subject

\begin{tabular}{|c|c|c|c|c|c|}
\hline Subject's code & Date: $08 / 13 / 17$ & Product & Outcome & Causal relationship & Instituted treatment \\
\hline NFFG & Post-intake heartburn & Test & Recovery without sequel & Probable & None Observation \\
\hline JFR & Mild headache & Test & Recovery without sequel & Probable & None Observation \\
\hline Subject's Code & Date: $07 / 30 / 17$ & Product & Outcome & Causal Relationship & Instituted treatment \\
\hline NFFG & Dry skin & Reference & Recovery without sequel & Probable & None Observation \\
\hline CCGD & Mild frontal headache & Reference & Recovery without sequel & Probable & None Observation \\
\hline GQP & Drowsiness & Reference & Recovery without sequel & Probable & None Observation \\
\hline
\end{tabular}

\section{Conclusion}

The Isoface ${ }^{\circledR}$ (Test Product), manufactured by Procaps S.A., Colombia, and the Roaccutane $\AA$, (Reference Product), manufactured by Catalent Germany, show pharmacokinetic parameters that allow to declare Bioequivalence between both formulations.

\section{Acknowledgements}

None.

\section{Conflict of interest}

The author declares there is no conflicts of interest in this work. 


\section{References}

1. Gollnick HPM. The treatment of acne. Drugs Today. 1992;5:353-361.

2. Abo Talib N, Tammam M, Hassan E. Bulletin of Faculty of Pharmacy, Cairo University. 2012;50:127-132.

3. Agarwal US, Besarwal RK, Bhola K. Indian J Dermatol Venereol Leprol. 2011;77:688-694.

4. Vargas M, Villarraga E, Batista M, et al. Bioequivalence Study of Two Formulations That Contain Isotretinoin 20mg Capsules in Healthy Colombian Volunteers. J Bioequiv Availab. 2016;8:274-277.

5. Food and Drugs Administration, Guidance for industry Statistical Approaches to Establishing Bioequivalence. 2009.

6. The European Agency for the Evaluation of Medicinal Products, EMA Committee for Proprietary Medicinal Products (CPMP). London: Note for guidance on the investigation of Bioavailability and Bioequivalence; 2001 .

7. Marzo A, Balant LP. An updated reappraisal addressed to applications of interchangeable multisource pharmaceutical products. Arzneimittelforschung. 1995;45(2):109-115.

8. Accutane FDA Label. Copyright (C) 2000-2008 by Roche Laboratories Inc. All rights reserved. 2017.

9. Republic of Colombia Ministry of Health Resolution. 1993.

10. World Medical Association Declaration of Helsinki, Ethical Principles for Medical Research, Involving Human Subjects. JAMA. 2013;310(20):2191-2194
11. Guidance for Industry Bioequivalence Studies with Pharmacokinetic Endpoints for Drugs Submitted Under an ANDA. U.S. Department of Health and Human Services Food and Drug Administration Center for Drug Evaluation and Research (CDER) December 2013

12. Jones K, O Donovan D, Horowitz M, et al. Effects of Posture on Gastric Emptying, Transpyloric Flow, and Hunger After a Glucose Drink in Healthy Humans. Dig Dis Sci. 2006;51(8):1331-1338.

13. Agarwal US, Besarwal RK, Bhola K. Indian J Dermatol Venereol Leprol. 2011;77:688-694

14. Guidance for Industry. Bioanalytical Method Validation U.S. Department of Health and Human Services. Food and Drug Administration. Center for Drug Evaluation and Research (CDER). Center for Veterinary Medicine (CVM).

15. Guidance on Validation of bioanalytical methods. Committefor medicinal products for human use (CHMP). Europeam medicines agency. 2009.

16. Perry R. Perspectives on the bioequivalence and therapeutic equivalence of generic formulations: An overview of the landscape. Clin Ther 2010;32(10):1796-1797.

17. Multisource (Generic) Pharmaceuticals Products: Guidelines On Registration Requirements to Establish Interchangeability, WHO Expert Committee On Specifications for Pharmaceutical Preparations, Thirty Four Report (WHO Technical Report Series, N” 9337), WHO 22006.

18. World Health Organization. Public health, innovation and intellectual property rights. 2006.

19. Julious SA. Tutorial in biostatistics: sample sizes for clinical trials with normal data. Stat Med. 2004;23(12):1921-1986. 